\title{
CHRONOLOGY OF NEOGENE SEDIMENTARY ROCKS \\ IN JACKSON HOLE, WYOMING
}

\author{
Douglas W. Burbank \\ Departinent of Geological Sciences \\ University of Southern California \\ Los Angeles
}

\section{Objectives}

The Miocene sediments of the Jackson Hole area constitute a unique sequence of terrestrial sediments. While much of the surrounding tertain was undergoing denudation during the Miocene, over $4000 \mathrm{~m}$ of volcaniclastic, lacustrine, and fluvial sediments accumulated in the vicinity of Jackson Hole. Recently completed paleontological and palynological studies have served to delineate complex biostratigraphic and climatic histories. The present research project is using magnetostratigraphy, fission-track dating, and $\mathrm{K}-\mathrm{Ar}$ dating to develop a chronology for the Miocene sediments. This chronology will permit the paleontological data to be examined in a precise temporal framework. Similarly, the rates and timing of climatic change as inferred from the pollen record will be constrained through these magnetostratigraphy studies.

The chronologic framework derived from this work will be used to define rates of sedimentation in the Miocene, to explore the timing of episodic volcanism, and to define the duration of tectonic events that can be inferced from the sedimentary record. Stratigraphic analyses of the detailed measured sections will be combined with petrographic study of representative lithological units and with the chronologic data in order to reconstruct the record of sedimentation during the Miocene in Jackson Hole.

\section{Methods}

The chronology being developed for the Miocene sediments of Jackson Hole will be based on a magnetic-polarity stratigraphy (MPS) which is calibrated by several radiometric dates. These dates will serve to tie the local inagnetostratigraphy into the global magnetic-polarity time scale (MPTS). In order to develop a magnetic stratigraphy, sampling sites are placed at regular stratigraphic intervals throughout the thickness of the formation being examined. At each site, 3 oriented samples are collected, and the site is marked, so that it can be revisited, if necessary. These samples are then cut into cubes and processed using a cryogenic magnetometer and facilities for alternating-field and thermal demagnetization. The resultant magnetic vectors for each sample are statistically averaged to produce a mean site direction. This mean direction is the basis for assigning a normal or reversed polarity to the site. The vertical sequence of site directions is then used to develop a magnetic-polarity stratigraphy. 
Sometimes the pattern of reversals can be matched unambiguously with the MPTS. However, more frequently there are several possible correlations. At this point, one or two radiometric dates can serve to constrain the local MPS. In this study, radiometric dates are obtainable from two techniques: fission-track dating of zircons extracted from volcanic ashes and $\mathrm{K}-\mathrm{Ar}$ dating of obsidian incorporated in coarse pumicites. Both approaches are being attempted.

In 1983, over $1000 \mathrm{~m}$ of stratigraphic section were measured and described. The main Teewinot sequence in the Elk Refuge was sampled using 65 magnetic sites. Additional samples were collected at Haybarn Hill on the Ellk Refuge and along the Kelly Road. Samples for lithologic analysis were collected from scattered outcrops throughout the section.

\section{Results}

The samples collected this summer are in the process of being analyzed. Test curves have been run for the magnetic studies, and several reversals have already been discovered. However, some of the samples are very weakly magnetized and will require additional sampling. The entire sequence has not yet been fully processed. Consequently, no conclusions can be reached at the present time on the chronologic constraints that will ultimately be placed on the sequence. The bulk samples for fission-track and $\mathrm{K}$-Ar dating are presently being processed. Dates should be forthcoming in 2 months.

It is only rarely that a single sampling traverse reveals an unambiguous polarity sequence. Thus, it is anticipated that an additional sampling effort will be necessary in the Teewinot Formation. It is anticipated that this will provide the additional detail required to develop reliable time constraints and to place other tectonic, sedimentary, paleontologic, and climatic data from the Teewinot in a tight chronologic framework.

\section{Conclusions}

The initial sampling phase of this study was successfully completed in August of 1983. These samples are now being analyzed and show promise of revealing a detailed magnetic-polarity stratigraphy. Similarly, radiometric dates are being produced on several suitable samples. At this time, no conclusions can be presented concerning the detailed chronology of the Miocene sediments in Jackson Hole. However, after further analysis and sampling, a new chronologic framework for geologic and climatic events in Jackson Hole should be forthcoming. 